\title{
Clinical Pharmacopsychology: Conceptual Foundations and Emerging Tasks
}

\author{
Giovanni A. Fava ${ }^{a}$ b Elena Tomba ${ }^{a}$ Per Bech ${ }^{c}$ \\ ${ }^{a}$ Department of Psychology, University of Bologna, Bologna, Italy; ${ }^{b}$ Department of Psychiatry, University at Buffalo, \\ Buffalo, NY, USA; ${ }^{C}$ Psychiatric Research Unit, Psychiatric Centre North Zealand, Copenhagen University Hospital, \\ Hillerød, Denmark
}

\section{Keywords}

Clinical pharmacopsychology · Clinimetrics · Rating scales · Behavioral toxicity · latrogenic comorbidity · Clinical psychology · Psychotherapy a change in terms of well-being and/or quality of life. Clinical pharmacopsychology offers a unifying framework for the understanding of clinical phenomena in medical and psychiatric settings. Research in this area deserves high priority.

(c) 2017 S. Karger AG, Basel

The term "pharmacopsychology" was introduced by Kraepelin [1] to indicate the effects of medical drugs on psychological functioning. He thought it was important to describe the psychological changes induced by pharmacotherapy. However, since the drugs he was studying were not adequate to induce clinical improvements in psychiatric patients, his interest in this area of research faded [2]. He was, however, among the first to propose the use of dose-response comparisons as an essential pharmacological criterion when determining the clinical effect of a drug [2].

Pierre Pichot [3] edited a volume of psychological measurements in psychopharmacology that was released in 1974. In his introduction, Pichot outlined new needs that derived from measuring the changes induced by psychotropic drugs. Unlike tests that were designed to assess stable traits (such as personality), psychological measure-

\section{KARGER}

(C) 2017 S. Karger AG, Basel 
ments in psychopharmacology were aimed to detect changes in the clinical state of the patient, while possessing validity and reliability. Two categories of instruments were collected by Pichot for the psychometric measurement in psychopharmacology: self-rating instruments (e.g., the Hopkins Symptom Checklist (HSCL) [4] and clinician-reported rating scales (e.g., the Hamilton Depression Rating Scale (HAM-D) [5] or the Brief Psychiatric Rating Scale (BPRS) [6]).

When Feinstein [7] made his first attempt to establish the discipline of clinimetrics within internal medicine he identified a crucial issue in determining the clinical outcome of therapeutic trials. Five years later Feinstein and Wells [8] introduced the new clinimetric taxonomy for rating change in a placebo-controlled trial of timolol maleate in patients with angina pectoris. By a transition index of change during treatment, Feinstein referred to the clinical observation of change by a global rating, taking into account the total information of the patient's functional capacity (occupational status, customary activities or sporadic activities). In a subsequent paper, Feinstein [9] suggested that the best way of validating a scale like the global clinical transition index of change in the patient's functional capacity during pharmacological treatment was through a consensus agreement of a panel of experts or other authorities.

In his textbook on clinimetrics, Feinstein [10], when measuring change in patient's clinical functioning during a treatment, differentiates between the global transition index and the repeated use of a rating scale score from baseline to endpoint in a trial of pharmacological drugs. In this textbook, Feinstein refers to the HAM-D [11]. Actually, Hamilton [12] noticed that change resulting from treatment is the most common use in clinical medicine for rating scales measuring symptoms of illness. As discussed by Tomba and Bech [13], the term clinimetrics as introduced by Feinstein has the clinical index of global improvement during treatment as its most unique contribution to clinical medicine.

Clinimetrics has a set of rules which govern the structure of indices, the choice of component variables, and the evaluation of consistency and validity. The rules differ from classical psychometrics, which developed outside the clinical field, mainly in the educational and social areas $[10,14-16]$. Indeed, the application of the classical psychometric model to the clinical challenges has been criticized in light of 2 major inadequacies $[17,18]$.

First, according to the most well-known model in classical psychometrics, the internal structure of items, as measured by statistical tests such as Cronbach's alpha, has

Clinical Pharmacopsychology often been the most important requirement for a rating scale. However, the same properties that give a scale a high score for internal consistency may obscure its ability to detect change [17]. The redundant nature of a scale's items may increase Cronbach's alpha, but decrease its sensitivity. The ability of a rating scale to discriminate between different groups of patients suffering from the same illness (e.g., depressed inpatients and outpatients) and to reflect changes in experiments in therapeutics such as drug trials has been defined by Kellner $[19,20]$ as sensitivity. Scales may be valid and reliable, but may lack sensitivity. This is particularly important when treatment effects are small and with limited sample sizes. The concept of sensitivity refers to both the detection of psychological states (whether symptoms or well-being) and their changes with treatment. In this latter context, responsiveness refers to the ability of a scale to measure clinically important changes in a trial [2]. In classical psychometrics, a high correlation is often regarded as evidence that the 2 scales measure the same factor. However, a high correlation does not indicate similar sensitivity. Two scales may have common content which insures a high positive correlation, but the items they do not share may be important in determining sensitivity $[19,20]$.

Second, in classical psychometrics all items are weighed the same, unlike in clinical medicine, where major and minor symptoms are often differentiated (e.g., Jones criteria for rheumatic fever). As a result, a patient with severe and pervasive anhedonia, incapacitating fatigue, and difficulties concentrating which make him unable to work would not be diagnosed as suffering from a major depressive disorder, despite the clinical intuition of potential benefit from pharmacotherapy. This diagnosis could be performed in a patient who barely meets the criteria for 5 symptoms. Severity is determined by the number of symptoms, not by their intensity or quality, to the same extent that a score in a depression self-rating scale depends on the number of symptoms that are scored as positive [17]. It should be noted, however, that the modern psychometric models introduced by Rasch [21] and Mokken [22] do not evaluate homogeneity in the classical psychometric sense (the equivalency of all items of a scale), but to what extent each item stands alone on the latent dimension of severity being examined. The mapping of locations of items is important when measuring change in a trial. In this sense, responsiveness to change is part of the clinimetric validity of a scale [2].

Clinical psychometrics is the term chosen by Bech [2] to indicate how clinimetric principles should supplement the standard psychometric analyses in rating scales in

Psychother Psychosom 2017;86:134-140 DOI: $10.1159 / 000458458$ 
psychiatry and pharmacology. Tomba and Bech [13] analyzed psychological measurements that satisfy clinimetric requirements. The term "clinical psychopharmacology," which derives from Kraepelin [1], has been advocated to indicate the clinical psychology approach to pharmacology $[23,24]$. Clinical pharmacopsychology was defined to be concerned with the application of clinimetric methods to the assessment of psychotropic effects of medications and the interaction of drugs with specific and nonspecific treatment ingredients [23, 24]. It should be differentiated from the approach of experimental psychology to pharmacology (experimental pharmacopsychology). Clinical psychopharmacology derives its data from observational and controlled studies on clinical populations, whereas experimental pharmacopsychology derives its data mainly from the laboratory and does not necessarily involve clinical populations. Clinical pharmacopsychology refers to the therapeutic use of medical drugs and should be differentiated from the study of the effects of substances used for other purposes [23,24].

The aim of this paper was to provide the conceptual foundations of the discipline, outlining its potential areas of application.

\section{The Inadequacy of Current Assessment Strategies in Psychopharmacology}

In clinical psychopharmacology, priority has been given to the standardization of rating scales that could be gold standards in the differentiation between a psychotropic drug and a placebo. Such standardization stems from the necessity of comparing studies in different countries which may have different languages $[2,3]$. As a result, a limited number of symptoms are selected, and psychological measurements are targeted to test efficacy [2]. These pragmatic needs, however, have limited the field and prevented developments: psychological evaluation is based on a limited range of symptoms that are considered to be characteristic of the psychiatric disorder that is examined [2]. For instance, there are at least 44 common symptoms of depression [25]. In trials, the 17-item HAM$\mathrm{D}$ has been the gold standard instrument for establishing and comparing the efficacy of treatments [26]. However, its sensitivity has been poor compared to subscale scores of the HAM-D based upon core symptoms of depression $[27,28]$ or global indices of change [26]. This is probably due to the fact that the HAM-D is a weak index of severity of depression [29]. Widely used and validated self-rating scales for depression were found to be even less sensi- tive than the HAM-D [30, 31]. One of the reasons for the high number of trials that fail to differentiate between active drug and placebo in psychopharmacology [32] may be the low sensitivity and/or inadequacy of the instruments that are employed.

Another major limitation has to do with the fact that targets of assessment have predominantly involved the desired effects of a drug. Bech [33] has proposed the pharmacopsychometric triangle, which consists in the assessment of clinically desired effects, adverse or side effects, and patient-reported quality of life, which can be a balance between the desired versus the undesired effects of the drug under examination. The assessment of the adverse events is certainly the neglected side of the triangle. Appraisal of adverse effects relies primarily on observational studies and data from routine clinical practice and may not emerge unless these effects are specifically measured and investigated with sensitive instruments.

Recently, Richardson and Doster [34] have suggested consideration of 3 dimensions in the process of evidencebased decision: baseline risk of poor outcomes from an index disorder without treatment, responsiveness to the treatment option, and vulnerability to the adverse effects of treatment. Assessment of such dimensions relies on Bech's triangle [33]: the clinical important changes that are concerned with wanted and expected treatment effects (point A), treatment-induced unwanted side effects (point B), and the patient's own personal experience of a change in terms of well-being and/or quality of life (point C) (Fig. 1).

Evidence-based medicine is focused on the potential benefits that therapy may entail as to baseline risk, but it is likely to neglect the other 2 dimensions [35]. A rational approach to treatment takes into account the balance between potential benefits and adverse effects applied to the individual patient [35]. The achievement of such balance is hindered by the varying quality and availability of different sources of information, which lead to a faulty clinical integration. The clinician needs to have a clear account of the potential benefits of a specific treatment, as well as of the predictors of responsiveness, and of the potential adverse events that may be triggered by the therapeutic act [35]. To accomplish this, a comprehensive clinimetric assessment of clinical variables that drug treatment mobilizes, subsumed under the definition of clinical pharmacopsychology, is in order. It is of historical interest that the initial phase of development of psychopharmacology was characterized by such a comprehensive approach [2].
136
Psychother Psychosom 2017;86:134-140 DOI: $10.1159 / 000458458$
Fava/Tomba/Bech 
Fig. 1. The pharmacopsychometric triangle.

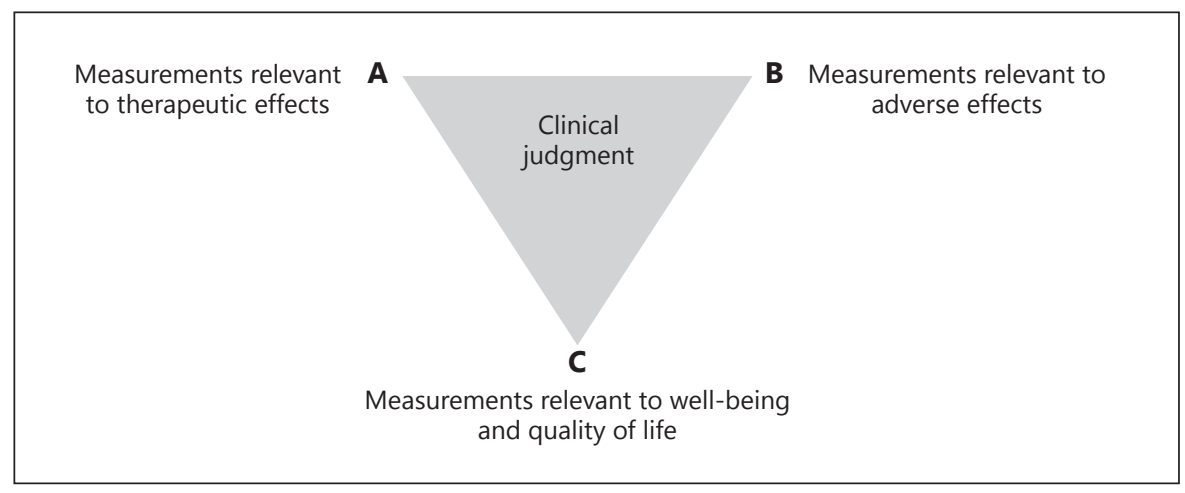

Fig. 2. Clinical pharmacopsychology and its areas of application.

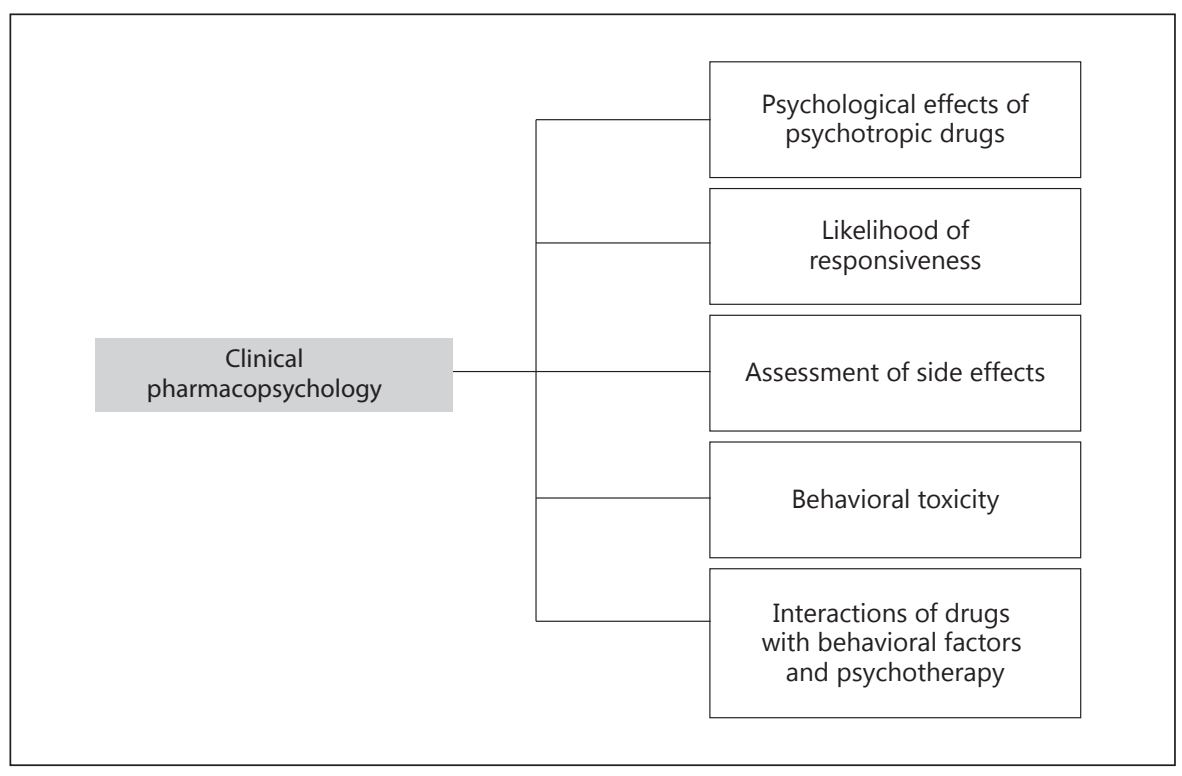

\section{Areas of Application}

The domains of clinical pharmacopsychology extend over several areas of application, which encompass the clinical benefits of psychotropic drugs, the characteristics that predict responsiveness to treatment, the vulnerabilities induced by treatment (side effects, behavioral toxicity, iatrogenic comorbidity), and the interactions between drug therapy and psychological variables (Fig. 2).

\section{Psychological Effects of Psychotropic Drugs}

In 1968, Di Mascio and Shader [36] criticized the tendency "to select, from among the many pharmacological actions that a drug may possess, a specific effect to consider as the main (therapeutic or beneficial) effect and to describe all others as side-effects" [36, p. 617]. They noted that a drug effect such as sedation or motor stimulation may be considered adverse for one patient, and yet thera-

Clinical Pharmacopsychology peutic and desired for another patient; within the same patient it may be of value at one stage of his/her illness and adverse at a later stage. For instance, antidepressant drugs in placebo-controlled studies have been found to decrease reactivity to social environment in depressed patients as assessed by the Clinical Interview for Depression [37]. The decrease may certainly be beneficial in an acute depressive state. However, it is conceivable, even though yet to be adequately investigated, that in a residual phase the same effect may entail apathy [38]. To ascertain this, however, one needs to rate reactivity to environmental stimuli and apathy, something that is omitted in the standard clinical trial $[37,38]$. Further, high sensitivity is required for detecting residual symptomatology, which was found to characterize the majority of patients who were judged to be remitted according to DSM criteria and no longer in need of active treatment [39]. Excessive reliance on symptoms that are part of diagnostic criteria of mental

Psychother Psychosom 2017;86:134-140 
disorders (e.g., major depressive disorder, generalized anxiety disorder) has impoverished clinical assessment in psychopharmacology and does not reflect the broad spectrum of variables that affect clinical presentations: subclinical distress [39], such as demoralization and irritable mood [40], psychological well-being and euthymia [4143], mental pain [44-47], social adjustment [48], and neuroticism $[49,50]$.

Indices may be observer- or self-rated. While observer-rated methods make full use of the clinical experience and comparison potential of the interviewer, self-rating methods allow a more direct assessment of the patient's subjective perceptions such as quality of life. While there is neither a precise nor an agreed definition of quality of life, research in this area seeks essentially 2 kinds of information: the functional status of the individual and the patient's appraisal of his/her own health. Indeed, the subjective perception of health status (e.g., lack of well-being, demoralization, difficulties fulfilling personal and family responsibilities) is as valid as that of the clinician in evaluating outcomes [51-53]. The recent emphasis on patient-reported outcomes, any report coming directly from patients about how they function or feel in relation to a health condition or its therapy $[54,55]$, is in line with this conceptualization.

\section{Likelihood of Responsiveness}

The likelihood of responsiveness to a certain drug treatment and the clinical characteristics that predict response are a crucial issue in psychopharmacology, even though, in recent years, excessive emphasis on the treatment of the average has decreased interest in these aspects $[15,34,35]$. While there is the clinical need of having the broadest picture of the effects of a drug, determination of responsiveness may be based on selected items [15]. Measuring response rates versus remission rates is another crucial issue in clinical trials [15]. Clinicians and researchers in clinical psychiatry often confound response to treatment with full recovery $[51,56]$.

\section{Assessing Side Effects}

Assessment of side effects that occur with any type of drug treatment tests, in addition to medical laboratory and investigational methods, requires a careful clinimetric collection of symptoms. The UKU [57] is an example of a scale that considerably improved the detection of side effects because of its comprehensive nature. For instance, sexual side effects are common and yet some of most underreported adverse effects associated with the use of antidepressants, and a growing body of evidence indicates that such side effects should be monitored by the use of specific instruments $[58,59]$. Further, as Karch and Lasagna [60] noted, the history of toxicology reminds us vividly of the lag that often occurs between the first introduction of a drug into humans and the recognition of certain adverse events from that drug. There is a need to update specific instruments for side effects with findings that may derive from case reports and clinical observations. For instance, the wide range of side effects that may ensue with long-term treatment with second generation antidepressants [59] would require specific methods of investigation.

\section{Behavioral Toxicity}

In 1968, Di Mascio and Shader [36] provided a conceptual framework for behavioral toxicity of psychotropic drugs (i.e., the pharmacological actions of a drug that, within the dose range in which it has been found to possess clinical utility, may produce alterations in mood and perceptual, cognitive, and psychomotor functions that limit the capacity of the individual or constitute a hazard to his/her well-being). The concept of behavioral toxicity encompasses adverse events that may be limited to the period of drug administration and/or persist long after their discontinuation. These latter phenomena can be subsumed under the rubric of iatrogenic comorbidity [61, $62]$. Behavioral toxicity may ensue with any type of medical drug. Examples related to antidepressant drug use may be the onset of suicidality and aggression, switching from unipolar to bipolar course, withdrawal phenomena upon discontinuation, and postwithdrawal persistent disorders $[59,62]$. Such phenomena require adequate clinimetric indices for their detection, as the late recognition of withdrawal syndromes after antidepressant drug discontinuation teaches $[63,64]$. Behavioral toxicity may apply also to drugs directed to medical conditions [65-67], which may induce depression, anxiety, and other psychiatric symptoms.

\section{Interaction of Medical Drugs with Behavioral \\ Variables and Psychotherapy}

Each therapeutic act may be seen as a result of multiple ingredients that may be specific or nonspecific: expectations, preferences, motivation, illness behavior, and patient-doctor interactions are examples of variables that may affect treatment outcome [68-70]. Such variables may be the object of study of clinical pharmacopsychology.

Forty years ago, Uhlenhuth et al. [71] examined the combinations of pharmacotherapy and psychotherapy in
Fava/Tomba/Bech 
psychiatric disorders. They outlined 4 models of interaction: (a) addition (the effects of 2 interactions combined equals the sum of their individual effects); (b) potentiation (the effect of 2 interventions combined is greater than the sum of their individual effects); (c) inhibition (the effect of 2 interventions combined is less that each individual effect); and (d) reciprocation (the effect of the 2 interventions combined equals the individual effect of the more potent intervention). Most of the studies that were reviewed were compatible with the reciprocal concept of interaction and only a few with additive effects [71]. Subsequent research has substantiated these conclusions in mood and anxiety disorders [72-74]. There are, however, some high-quality and well-designed individual studies that suggest that the addition of a benzodiazepine or an antidepressant to cognitive behavioral treatment of anxiety disorders could be detrimental compared to placebo at follow-up [75-78]. Again, clinical pharmacopsychology could be crucial for disclosing the nature of these relationships.

\section{Conclusions}

Clinical pharmacopsychology consists of the application of clinical psychology to the full understanding of pharmacological effects. At a time when the progress of psychopharmacology is hindered by major financial conflicts of interest that cast doubts on its credibility $[79,80]$, fascinating vistas for the independent features of clinical pharmacopsychology are opening up. They should be welcome to all those who are disillusioned with the disappointing practical results of recent research in psychopharmacology and should become a channel of funding and attention.

\section{References}

1 Kraepelin E: Uber die Beeinflussung einfach- 12 Hamilton M: Some notes on rating scales. 23 Fava GA, Staccini L, Delle Chiaie R, Belaise C, er psychischer Vorgange durch einige ArzStatistician 1968;18:11-17. Tomba E: Farmacopsicologia clinica. Riv neimittel. Jena, Fischer Verlag, 1892.

2 Bech P: Clinical Psychometrics. Oxford, Wiley-Blackwell, 2012.

$\checkmark 13$ Tomba E, Bech P: Clinimetrics and clinical psychometrics: macro- and micro-analysis. Psychother Psychosom 2012;81:333-343.

3 Pichot P: Introduction; in Pichot P (ed): Psychological Measurements in Psychopharmacology. Basel, Karger, 1974, pp 1-7.

4 Derogatis LR, Lipman RS, Rickels K, Uhlenmuth EH, Covi L: The Hopkins Symptom Checklist (HSCL): a measure of primary symptom dimensions; in Pichot P (ed): Psychological Measurements in Psychopharmacology. Basel, Karger, 1974, pp 79-110.

$\checkmark 5$ Hamilton M: General problems of psychiatric rating scales (especially for depression); in $\mathrm{Pi}$ chot P (ed): Psychological Measurements in Psychopharmacology. Basel, Karger, 1974, pp 125-138.

6 Overall JE: The Brief Psychiatric Rating Scale in psychopharmacology research; in Pichot $\mathrm{P}$ (ed): Psychological Measurements in Psychopharmacology. Basel, Karger, 1974, pp 67-78.

7 Feinstein AR: On exorcising the ghost of Gauss and the curse of Kelvin. Clin Pharmacol Ther 1971;12:1003-1016.

$\checkmark 8$ Feinstein AR, Wells CK: A new clinical taxonomy for rating angina pectoris. Am Heart J 1977;93:172-182.

$\checkmark 9$ Feinstein AR: The Jones criteria and the challenge of clinimetrics. Circulation 1982;66:15.

10 Feinstein AR: Clinimetrics. New Haven, Yale University Press, 1987.

$\checkmark 11$ Hamilton M: Development of a rating scale for primary depressive illness. Br J Soc Clin Psychol 1967;6:278-296.
14 Fava GA, Tomba E, Sonino N: Clinimetrics: the science of clinical measurements. Int J Clin Pract 2012;66:11-15.

$\checkmark 15$ Bech P: Clinimetric dilemmas in outcome scales for mental disorders. Psychother Psy-

16 Piolanti A, Offidani E, Guidi J, Gostoli S, Fava GA, Sonino N: Use of the Psychosocial Index: a sensitive tool in research and practice. Psychother Psychosom 2016;85:337-345.

17 Fava GA, Ruini C, Rafanelli C: Psychometric theory is an obstacle to the progress of clinical research. Psychother Psychosom 2004;73: 145-148.

18 Bech P: Modern psychometrics in clinimetrics: impact on clinical trials of antidepressants. Psychother Psychosom 2004;73:134138.

19 Kellner R: Improvement criteria in drug trials with neurotic patients. Part 2. Psychol Med 1972;2:73-80.

20 Kellner R: The measurement of depression and anxiety; in den Boer JA, Sitsen JMA (eds.): Handbook of Depression and Anxiety. New York, Dekker, 1994, pp 133-158.

21 Rasch G: Probabilistic Models for Some Intelligence and Attaintment Tests. Copenhagen, Danish Institute for Educational Research, 1960 (expanded edition: Chicago, Chicago University Press, 1980).

22 Mokken RJ: Theory and Practice of Scale Analysis. Berlin, Mouton, 1971. chosom 2016;85:323-326. Psichiatr 2014;49:251-254.

24 Guidi J, Fava GA: Emerging trends in clinical psychology. Riv Psichiatr 2014;49:227.

25 Pedrelli P, Blais MA, Alpert JEW, Shelton RC, Walker RS, Fava, M: Reliability and validity of the Symptoms of Depression Questionnaire (SDQ). CNS Spectr 2014;19:535-546.

26 Demyttenaere K, De Fruyt J: Getting what you ask for: on the selectivity of depression rating scales. Psychother Psychosom 2003;72:61-70.

27 Faries D, Herrera J, Rayamajhi J, De Brota D, Demitrack M, Potter WZ: The responsiveness of the Hamilton Depression Rating Scale. J Psychiatr Res 2000;34:3-10.

28 Timmerby N, Andersen JH, Sondergaar S, Ostergaard SD, Bech P : A systematic review of the clinimetric properties of the 6-item version of the Hamilton Depression Rating Scale (HAM-D6). Psychother Psychosom 2017;86: 141-149.

29 Gibbons RD, Clark DC, Kupfer DJ: Exactly what does the Hamilton Depression Rating Scale measure? J Psychiatr Res 1993;27:259-273.

>30 Carroll BJ, Fielding JM, Blashki TG: Depression rating scales. Arch Gen Psychiatry 1973; 28:361-366.

$>31$ Kearns NP, Cruickshank CA, McGuigan KJ, Riley SA, Shaw SP, Snaith RP : A comparison of depression rating scales. Br J Psychiatry 1982;141:45-49.

>32 Fava M, Evins AE, Dorer DJ, Schoenfeld DA: The problem of the placebo response in clinical trials for psychiatric disorders: culprits, possible remedies, and a novel study design approach. Psychother Psychosom 2003;72: 115-127. 
33 Bech P: Applied psychometrics in clinical psychiatry. Acta Psychiatr Scand 2009;120: 400-409.

34 Richardson WS, Doster LM: Comorbidity and multimorbidity need to be placed in the context of a framework of risk, responsiveness, and vulnerability. J Clin Epidemiol 2014; 67:244-246.

-35 Fava GA, Guidi J, Rafanelli C, Sonino N: The clinical inadequacy of evidence-based medicine and the need for a conceptual framework based on clinical judgment. Psychother Psychosom 2015;84:1-3.

36 Di Mascio A, Shader RI: Behavioral toxicity of psychotropic drugs. Conn Med 1968;32:617620.

>37 Guidi J, Fava GA, Bech P, Paykel E: The Clinical Interview for Depression. Psychother Psychosom 2011;80:10-27.

>38 Rothschild AJ, Raskin J, Wamg CN, Marangell $\mathrm{LB}$, Fava $\mathrm{M}$ : The relationship between change in apathy and changes in cognition and functional outcomes in currently nondepressed SSRI-treated patients with major depressive disorder. Compr Psychiatry 2014; 55:1-10.

-39 Fava GA, Rafanelli C, Tomba E: The clinical process in psychiatry: a clinimetric approach. J Clin Psychiatry 2012;73:173-184.

40 Porcelli P, Guidi J: The clinical utility of the Diagnostic Criteria for Psychosomatic Research. Psychother Psychosom 2015;84:265272.

41 Fava GA, Bech P: The concept of euthymia. Psychother Psychosom 2016;85:1-5.

42 Hasler G: Well-being: an important concept for psychotherapy and psychiatric neuroscience. Psychother Psychosom 2016;255-261.

43 Bech P, Carrozzino D, Austin SF, Moller SB, Vassend O: Measuring euthymia within the Neuroticism Scale of the NEO Personality Inventory. J Affect Disord 2016;15:193-199.

44 Tossani E: The concept of mental pain. Psychother Psychosom 2013;82:67-73.

45 Blasco-Fontecilla H, Baca-Garcia E, Courtet $\mathrm{P}$, Garcia Nieto R, de Leon J: Horror vacui emptiness might distinguish between major suicide repeaters and non-major suicide repeaters. Psychother Psychosom 2015;84:117119.

46 de Leon J, Baca-Garcia E, Blasco-Fontecilla H: From the serotonin model of suicide to a mental pain model of suicide. Psychother Psychosom 2015;84:323-329.

-47 Verrocchio MC, Carrozzino D, Marchetti D, Andreasson K, Fulcheri M, Bech P: Mental pain and suicide. Front Psychiatry 2016;7: 108.

48 Bech P: Social functioning: should it become an endpoint in trials with antidepressants. CNS Drugs 2005;19:13-24.

$\checkmark 49$ Tyrer P, Tyrer H, Guo B: The general neurotic syndrome: a re-evaluation. Psychother Psychosom 2016;85:193-197.
0 Bech P, Rickels K: The items predicting nonremission after 6 months of treatment of patients with generalized anxiety disorder covered the Eysenck neuroticism components of anxiety, interpersonal sensitivity and depression. Psychother Psychosom 2016;85:229230.

51 Bech P: Measurement of psychological distress and well-being. Psychother Psychosom 1990;54:77-89.

52 Rodriguez-Urrutia A, Eiroa-Orosa FJ, Accarino A, Malagelada C, Azpiroz F: Incongruence between clinicians' assessments and selfreport functioning is related to psychopathology among patients diagnosed with gastrointestinal disorders. Psychother Psychosom 2016;85:244-245.

53 Topp CW, Østergaard SD, Søndergaard S, Bech P: The WHO-5 Well-Being Index: a systematic review of the literature. Psychother Psychosom 2015;84:167-176.

54 Bottomley A, Jones D, Claassens L: Patientreported outcomes: assessment and current perspectives of the guidelines of the Food and Drug Administration and the reflection paper of the European Medicine Agency. Eur J Cancer 2009; 45:347-353.

55 Clancy C, Collins FS: Patient-Center Outcomes Research Institute: the intersection of science and health care. Sci Transl Med 2010; 3:37.

56 Fava GA: The concept of recovery in affective disorders. Psychother Psychosom 1996;65: 2-13.

57 Lingjaerde O, Ahlfors UG, Bech P, Dencker SJ, Elgen K. The UKU side effect rating scale. A new comprehensive rating scale for psychotropic drugs and a cross-sectional study of side effects in neuroleptic-treated patients. Acta Psychiatr Scand Suppl 1987;334:1-100.

58 Balon R, Segraves RT: Survey of treatment practices for sexual dysfunction(s) associated with antidepressants. J Sex Marital Ther 2008; 34:353-365.

59 Carvalho AF, Sharma MS, Brunoni AR, Vieta E, Fava GA: The safety, tolerability and risks associated with the use of newer generation antidepressant drugs. Psychother Psychosom 2016;85:270-288.

60 Karch FE, Lasagna L: Adverse drug reactions. A critical review. JAMA 1975;234:1236-1241.

61 Fava GA, Cosci F, Tomba E: Iatrogenic comorbidity in mental health. Psychother Psychosom 2015;84(suppl 1):22.

62 Fava GA, Cosci F, Offidani E, Guidi J: Behavioral toxicity revisited: iatrogenic comorbidity in psychiatric evaluation and treatment. J Clin Psychopharmacol 2016;36:550-553

63 Fava GA, Gatti A, Belaise C, Guidi J, Offidani E: Withdrawal symptoms after selective serotonin reuptake inhibitor discontinuation: a systematic review. Psychother Psychosom 2015;84:72-81.

64 Chouinard G, Chouinard VA: New classification of selective serotonin reuptake inhibitor withdrawal. Psychother Psychosom 2015;84: 63-71.
65 Shader RI (ed): Psychiatric Complications of Medical Drugs. New York, Raven Press, 1972.

66 Whitlock FA: Adverse psychiatric reactions to modern medication. Aust NZ J Psychiatry 1981;15:87-103.

67 Tisdale JE, Miller DA (eds): Drug-Induced Diseases, ed 2. Bethesda, American Society of Health-System Pharmacists, 2010.

68 Rickels K: Non-specific factors in drug therapy. Springfield, Charles C Thomas, 1968.

69 Zilcha-Mano S, Roose SP, Barber JP, Rutherford BR: Therapeutic alliance in antidepressant treatment: cause or effect of symptomatic levels? Psychother Psychosom 2015;84: 177-182.

70 Schedlowski M, Enck P, Rief W, Bingel U: Neuro-bio-behavioral mechanisms of placebo and nocebo responses: implications for clinical trials and clinical practice. Pharmacol Rev 2015;67:697-730.

71 Uhlenhuth EH, Lipman RS, Covi L: Combined pharmacotherapy and psychotherapy. J Nerv Ment Dis 1969;148:52-64.

72 Fava GA, Tomba E: New modalities of assessment and treatment planning in depression. CNS Drugs 2010;24:453-465.

73 Forand NR, de Rubeis RJ, Amsterdam JD: Combining medication and psychotherapy in the treatment of major mental disorders; in Lambert MJ (ed): Bergin and Garfield's Handbook of Psychotherapy and Behavior Change, ed 6. Hoboken, Wiley, 2013, pp 735774.

74 Guidi J, Tomba E, Fava GA: The sequential integration of pharmacotherapy and psychotherapy in the treatment of major depressive disorder: a meta-analysis of the sequential model and a critical review of the literature. Am J Psychiatry 2016;173:128-137.

75 Marks IM, Swinson RP, Basoglu M, Kuch K, Noshirvani H, O’Sullivan G, Lelliott P, Kirby M, McNamee G, Sengun S, Warkwick K: Alprazolam and exposure alone and combined in panic disorder with agoraphobia. Br J Psychiatry 1993;162:776-787.

76 Barlow DH, Gorman JM, Shear MK, Woods SW: Cognitive behavioral therapy, imipramine and their combination for panic disorder. JAMA 2000;283:2529-2536.

77 Haug TT, Blomhoff S, Hellstrom K, Holme I, Humble M, Madsbur HP, Wold JE: Exposure therapy and sertraline in social phobia. $\mathrm{Br} \mathrm{J}$ Psychiatry 2003;182:312-318.

78 Nordahl HM, Vogel PA, Morken G, Stiles TC, Sandvik P, Wells A: Paroxetine, cognitive therapy or their combination in the treatment of social anxiety disorder with or without avoidant personality disorder. Psychother Psychosom 2016;85:346-356.

79 Fava GA: Conflict of interest in psychopharmacology: can Dr. Jekyll still control Mr. Hyde? Psychother Psychosom 2004;73:1-4.

80 Fava GA: The hidden costs of financial conflicts of interest in medicine. Psychother Psychosom 2016;85:65-70. 